\title{
Performance of iohexol determination in serum and urine by HPLC: Validation, risk and uncertainty assessment
}

\author{
Etienne Cavalier ${ }^{\mathrm{a}, *}$, Eric Rozet ${ }^{\mathrm{b}}$, Nathalie Dubois ${ }^{\mathrm{c}}$, Corinne Charlier $^{\mathrm{c}}$, Philippe Hubert ${ }^{\mathrm{b}}$, Jean-Paul Chapelle ${ }^{\mathrm{a}}$, \\ Jean-Marie Krzesinski ${ }^{d}$, Pierre Delanaye ${ }^{\mathrm{d}}$
}

a Department of Clinical Chemistry, University of Liège, CHU Sart-Tilman, B-4000 Liège, Belgium

${ }^{\mathrm{b}}$ Department of Analytical Chemistry, University of Liège, CHU Sart-Tilman, B-4000 Liège, Belgium

c Department of Toxicology, University of Liège, CHU Sart-Tilman, B-4000 Liège, Belgium

d Department of Nephrology and Hypertension, University of Liège, CHU Sart-Tilman, B-4000 Liège, Belgium

\section{A R T I C L E I N F O}

\section{Article history:}

Received 9 June 2008

Received in revised form 1 July 2008

Accepted 13 July 2008

Available online 18 July 2008

\section{Keywords:}

Glomerular filtration rate

Analytical validation

Measurement uncertainty

Iohexol

Reference method

\begin{abstract}
A B S T R A C T
Background: Determination of glomerular filtration rate plays an important role in nephrological practice. Iohexol is a reference marker for glomerular filtration rate determination. It is available and safe. The aim of this study was to develop a simple, efficient and easy to use analytical method for the quantification of iohexol in serum and urine by high performance liquid chromatography and to thoroughly validate this method.

Methods: The HPLC method was inspired from the method published by Krutzen. The e.noval software V2.0 (Arlenda, Liège, Belgium) was used to compute all validation results.

Results: The validation results indicate that the method will give accurate and reliable results for serum values ranging from 12.95 to $1295 \mu \mathrm{g} / \mathrm{ml}$ and for urine values ranging from 86.0 to $4144 \mu \mathrm{g} / \mathrm{ml}$. In routine practice, iohexol concentrations found in plasma after injection range from 40 to $600 \mu \mathrm{g} / \mathrm{ml}$. The expected urinary values are much wider. One should not hesitate to dilute urine samples to fit with the validated range over $5000 \mu \mathrm{g} / \mathrm{ml}$. Conclusion: This is the first time that a reference method for the determination of GFR is validated with such a rigorous and thorough protocol. Contrary to other GFR markers, iohexol is now strongly validated from an analytical point of view.
\end{abstract}

(c) 2008 Elsevier B.V. All rights reserved.

\section{Introduction}

Determination of glomerular filtration rate (GFR) plays an important role in daily nephrological practice. Indeed, its determination is crucial to diagnose chronic kidney diseases (CKD) or evaluate risks of developing CKD.

Several steps are required in order to achieve a reliable GFR. The first point is the selection of the GFR marker, the substance that will be monitored in order to determine the filtration rate. The ideal features of the substance to be monitored in order to evaluate the GFR are to appear endogenously in the plasma at constant rate, be freely filtered by the glomerulus without renal tubule absorption or secretion and without extra-renal elimination [1]. This ideal substance does exist but is exogenous: inulin (a fructose polymer). The renal clearance of inulin is thus the "gold standard" for the GFR measurement. However, its application is expensive and tedious [2]. Moreover, inulin is not always easily available on the market. The most used marker in clinical practice is endogenous and is serum creatinine. However, it does not comply to all of

\footnotetext{
* Corresponding author. Service de Chimie Médicale, Centre Hospitalier Universitaire de Liège, Domaine du Sart-Tilman, B-4000 Liège, Belgium. Tel.: +32 4 3667692; fax: +32 43667691.

E-mail address: Etienne.cavalier@chu.ulg.ac.be (E. Cavalier).
}

these last features [3] and it is indeed a poor marker for GFR, especially in specific population like obese, anorectic and transplanted patients $[4,5]$. In these specific patients and in clinical nephrological studies, a precise GFR measurement is needed. As inulin clearance measurement is not easy, other methods have been developed as isotopic methods such as ${ }^{51} \mathrm{Cr}$-ethylenediaminetetra-acetic acid (EDTA) (although not available in the United States) or ${ }^{99}$ Tc-diethylenetriaminepentaacetic acid (DTPA) $[6,7]$. However these markers require special handling, radiation exposure and are costly. Contrast agents like iothalamate or iohexol $(N$, $N$ '-bis (2,3-dihydroxypropyl)-5-( $N$-2,3-dihydroxypropyl)acetamido)2,4,6-triiodoisophtalamide) are also available and have the features of the ideal marker together with being easily available and safe. Thus iohexol clearance is replacing inulin clearance as a marker of choice for GFR $[2,8-10]$.

Once the ideal marker has been chosen, the next step is the development of an accurate quantitative analytical method to obtain reliable concentration values of this marker in the serum. The objective of any quantitative analytical method is to obtain results that are close enough to the unknown true value of analyte under investigation in the samples analyzed. One way to demonstrate that the analytical method will provide reliable results is to perform method validation. The objective of method validation is thus to give guarantees that most of the results that will be generated during routine use of this method 
will be close enough to unknown true value of analyte. If the validation fails to give this guarantee then decision based on the results obtained by this method will be unreliable and may cause errors in diagnostics: declaring a healthy patient as ill and vice versa.

Various chromatographic methods have been described for iohexol determination, mainly in serum [11-13]. However, one should notice that these methods have been poorly analytically validated. Even more, validation for the determination in urine matrix with these methods is clearly lacking.

Thus, the aim of this paper is first to develop a simple, efficient and easy to use routinely analytical method for the quantification of iohexol in serum and urine by high performance liquid chromatography (HPLC) inspired from the method published by Krutzen et al. [12]. Secondly, a thorough validation of this method is performed, which will provide guarantees about the accuracy and thus the reliability of the results that will be obtained by this method during future day to day analysis. In order to attain maximum guarantees risk to obtain results outside pre-specified acceptance limits is provided as well as the measurement uncertainty.

\section{Materials and methods}

\subsection{Terminology}

Before going on with the main aims of this paper it is important to define several crucial terms, which are sources of confusion depending on the environment in, which one works or, which are not usually well known.

- Accuracy, as defined in ISO documents or in documents ICH Q2R1 section terminology, is "the closeness of agreement between the value, which is accepted either as a conventional true value or an accepted reference value and the value found." [14-23]. It therefore refers to total measurement error.

Trueness refers to "the closeness of agreement between the average value obtained from a large series of test results and an accepted reference value" $[15,16,19]$. This concept is therefore related to the systematic error of a measurement process.

- Precision refers to "the closeness of agreement (degree of scatter) between a series of measurements obtained from multiple sampling of the same homogeneous sample under the prescribed conditions." [14-23].This is related to the random error of a measurement process.

As can be understood from these definitions, the main point is that accuracy is the simultaneous combination of both systematic and random errors, i.e. total error $[15,16,19]$.

- Uncertainty of measurement is defined as "a parameter associated with the result of a measurement, that characterizes the dispersion of the values that could reasonably be attributed to the measurand" [19-21].

- $\beta$-expectation tolerance intervals are intervals that contain a proportion $\beta$ of the individual values, such as results, of the population under investigation (e.g. 0.95). These intervals allow to describe the entire population and are less known than confidence intervals [22]. These intervals are called " $\beta$-expectation tolerance intervals" (also known as "mean coverage tolerance intervals" or "prediction intervals"). If $\beta=0.95$, this means that on average, $95 \%$ of the future individual values (results) of the population are included in the interval [L; U] [23].

\subsection{Chemicals}

Iohexol (Omnipaque TM) was purchased from Amersham Health (South Plainfield, NJ, USA). Perchloric and orthophosphoric acid were both reagent grade and were purchased from Merck (Darmstadt, Germany) and HPLC grade acetonitrile from LabScan (Dublin, Ireland).

Ultrapure distilled and deionized water was prepared in-house and filtered prior to use.

\subsection{HPLC equipment and mobile phase}

The HPLC equipment consisted of a Hewlett-Packard (HP) 1100 Model (Agilent Technologies, Palo Alto, CA, USA). The Lichrospher analytical column (Merck; $250 \times 4 \mathrm{~mm}$ I.D.; particle size: $5 \mu \mathrm{M}$ ) was packed with $\mathrm{C} 18$ material.

The mobile phase consisted of a mixture of distilled water and acetonitrile (95:5: v/v) adjusted to $\mathrm{pH} 3.0$ with orthophosphoric acid. The separation was performed isocratically with a flow rate of $1.0 \mathrm{ml} / \mathrm{min}$. Typical HPLC operating pressure was approximately 70 bars at a thermostatised column oven temperature of $40^{\circ} \mathrm{C}$.

An injection volume of $20 \mu \mathrm{l}$ for serum and urine samples was accomplished using the HP 1100 autosampler. Detection was achieved with the HP 1100 DAD detector at an absorbance wavelength of $254 \mathrm{~nm}$.

\subsection{Standard and control preparation}

Standards stock solutions of iohexol $(520 \mathrm{mg} / \mathrm{ml}$ in deionized water) were prepared and stored at $4{ }^{\circ} \mathrm{C}$. Working serum and urine standards as well as control samples were prepared by dilution of the stock solutions with adequate volumes of blank human serum and urine.

\subsection{Calculations}

The e.noval software V2.0 (Arlenda, Liège, Belgium) was used to compute all validation results and build the accuracy profiles.

\subsection{Serum and urine samples preparation}

To deproteinize the serum matrix, $100 \mu \mathrm{l}$ of serum were treated with $100 \mu \mathrm{l}$ of $5 \%$ perchloric acid. The tubes were then spun at $11,000 \mathrm{~g}$ at $4{ }^{\circ} \mathrm{C}$ during $10 \mathrm{~min}$. The supernatant was directly transferred to glass HPLC vials.

Fifty microlitres of urine were directly diluted in the glass autosampler vial with $1 \mathrm{ml}$ of deionised water and vortex mixed for $10 \mathrm{~s}$

\section{Results}

\subsection{Method optimization}

The method previously published by Krutzen et al. [12], was modified by first, adjusting the $\mathrm{pH}$ of the mobile phase from 2.5 to 3.0, then the volume of perchloric acid necessary to precipitate the serum proteins was reduced from 5 volumes to 1 volume and finally the flow rate reduced from 1.5 to $1 \mathrm{ml} / \mathrm{min}$. These conditions provided good peak shape. The iohexol isomers eluted at 4.3 and 4.7 min (Fig. 1).

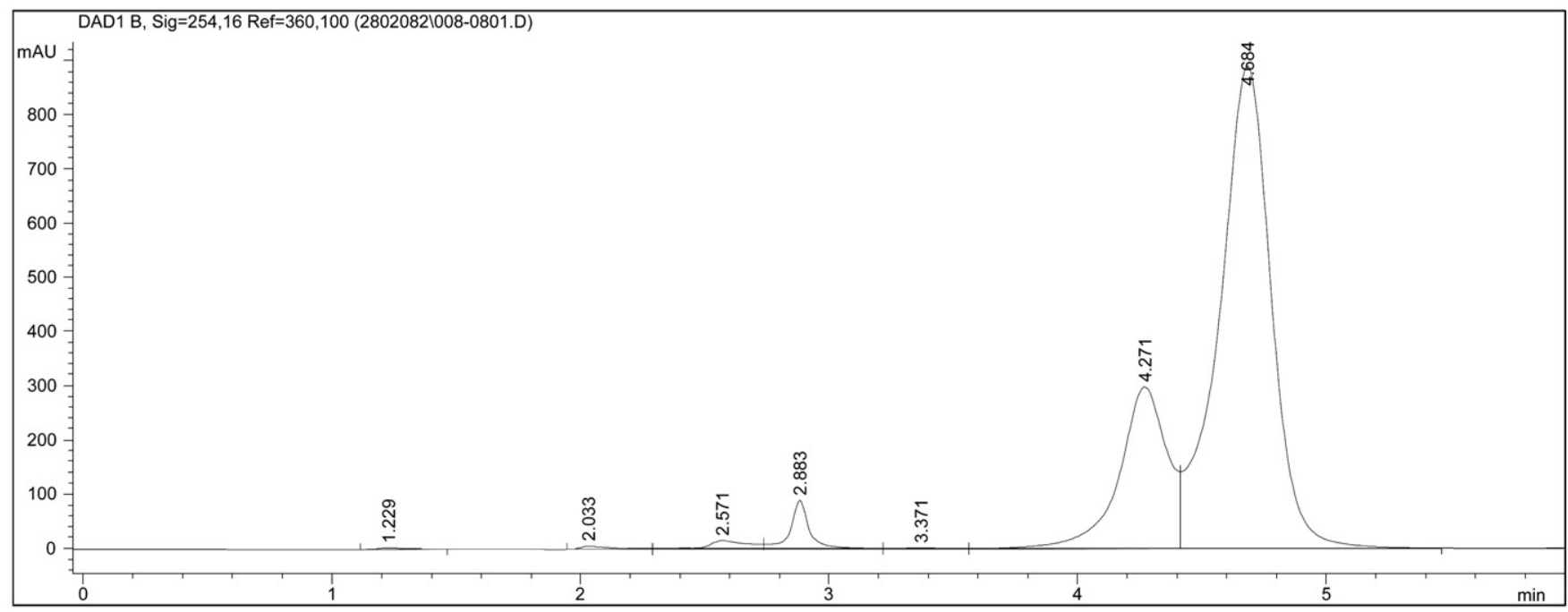

Fig. 1. Chromatogram of a serum $130 \mu \mathrm{g} / \mathrm{ml}$ iohexol calibrator. 


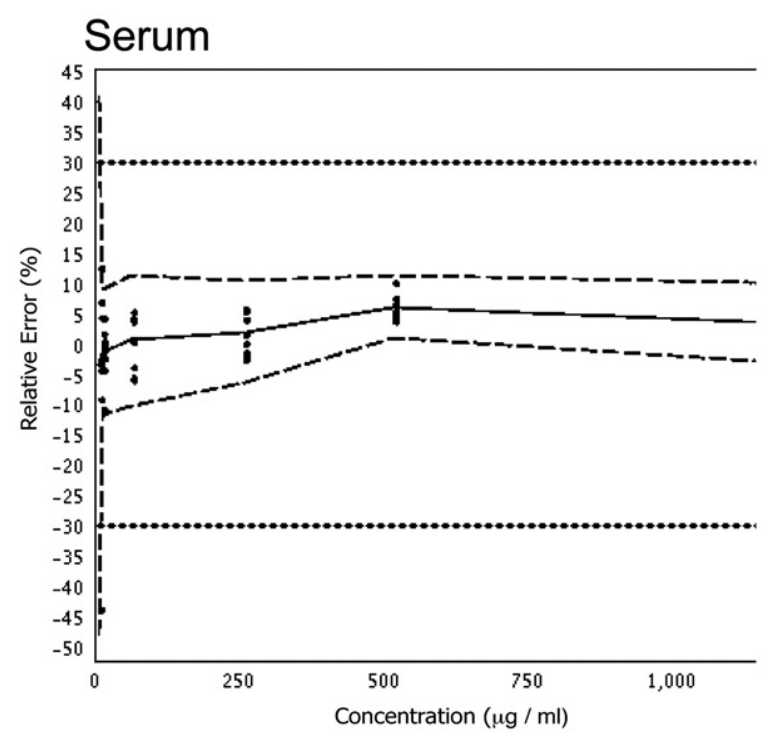

Urine

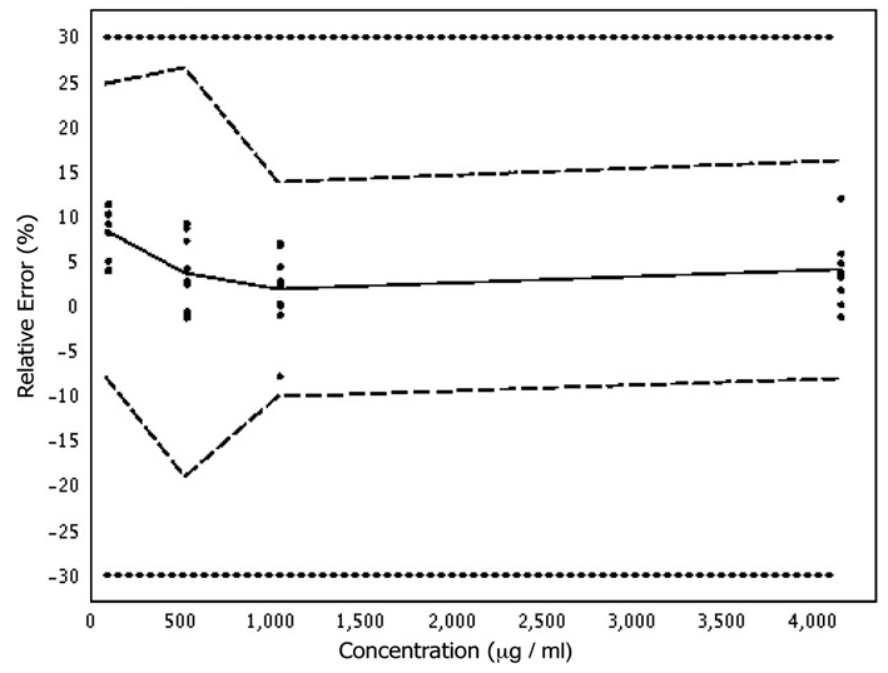

Fig. 2. Accuracy profiles, using a for calibration curve a weighted $(1 / X)$ linear regression model for serum and urine. Acceptance limits (....), $\beta$-expectations tolerance limits (----) and relative bias (_ $)$.

\subsection{Method validation}

\subsubsection{Selectivity}

The absence of interfering endogenous components of urine and serum at the retention time of iohexol was demonstrated after analysis of serum and urine spiked with iohexol and blank samples from six different sources of the same matrices (data not shown).

\subsubsection{Response function}

The response function is, within a certain range, the relationship between the response observed and the concentration of the analyte in the sample [24]. Thus, the selection of the calibration curve for the quantification of iohexol in the two matrices should be the fit for purpose response function [25]. To determine the most adequate one for our goal, different calibration models have been evaluated. As iohexol is not naturally present in serum or urine, the calibration curves were prepared by spiking a pool of serum and of urine in order to reach 7 concentration levels ranging from 6.47 to $1295 \mu \mathrm{g} / \mathrm{ml}$ for serum and from 52.0 to $4144 \mu \mathrm{g} / \mathrm{ml}$ for urine, respectively. Each calibration point was analyzed in duplicate on three consecutive days.

Independent validation standards were also prepared by proceeding in the same way: for serum, 6 validation standards ranging from
8.63 to $1295 \mu \mathrm{g} / \mathrm{ml}$ were analyzed in triplicate on three consecutive days and for urine, 4 validation standards ranging from 86.0 to $4144 \mu \mathrm{g} / \mathrm{ml}$ were analyzed in triplicate on three consecutive days.

From the results obtained, the concentrations of the validation standards were back-calculated to determine the mean relative bias, the standard deviation for intermediate precision and finally the upper and lower $\beta$-expectation tolerance limits at 95\% level $[16,26]$.

Different accuracy profile were thus plotted to select the most convenient regression model for the analytical method. The acceptance limits were set at $\pm 30 \%$ as recommended [26]. As shown in Fig. 2, the best response function for serum as well as for urine was achieved with the weighted $(1 / X)$ linear regression. The response functions obtained by applying these regression models are presented in Table 1.

\subsubsection{Trueness}

Trueness, expressed in terms of relative bias (\%), was calculated from the validation standards $[16,24]$. As can been seen in Table 1 , trueness was acceptable (relative bias smaller than 10\%) for both matrices serum and urine.

\subsubsection{Precision}

The precision of the method was determined by computing the Relative Standard Deviations (RSDs) for repeatability and timedifferent intermediate precision at each concentration level of the validation standards $[16,24,26]$. For serum and urine, the precision at each concentration level of the validation standards did not exceed 15\% (Table 1).

\subsubsection{Accuracy, LOQ and LOD}

Accuracy takes into account the total error (sum of the systematic and random errors) of the test results $[16,24,26]$. As shown in Table 1, the relative upper and lower $\beta$-expectation tolerance limits (\%) did not exceed the acceptance limits $( \pm 30 \%)$ for each concentration level and for both matrices.

Table 1

Method validation for iohexol determination in serum and urine.

\begin{tabular}{|c|c|c|c|c|}
\hline Validation criterion & \multicolumn{2}{|l|}{ Serum } & \multicolumn{2}{|l|}{ Urine } \\
\hline Response function & \multicolumn{2}{|c|}{$\begin{array}{l}\text { Calibration range ( } 7 \text { points): } \\
6.47-1295 \mu \mathrm{g} / \mathrm{ml}\end{array}$} & $\begin{array}{l}\text { Calibration range ( } 7 \text { points): } \\
52.0-4144 \mu \mathrm{g} / \mathrm{ml}\end{array}$ & near \\
\hline Trueness & Concentration & Relative bias & Concentration & Relative bia \\
\hline Level 1 & $8.63 \mu \mathrm{g} / \mathrm{ml}$ & $-3.4 \%$ & $86 \mu \mathrm{g} / \mathrm{ml}$ & $8.4 \%$ \\
\hline Level 2 & $12.95 \mu \mathrm{g} / \mathrm{ml}$ & $-1.3 \%$ & $518 \mu \mathrm{g} / \mathrm{ml}$ & $3.7 \%$ \\
\hline Level 3 & $64.75 \mu \mathrm{g} / \mathrm{ml}$ & $0.7 \%$ & $1036 \mu \mathrm{g} / \mathrm{ml}$ & $1.9 \%$ \\
\hline Level 4 & $259 \mu \mathrm{g} / \mathrm{ml}$ & $2.0 \%$ & $4144 \mu \mathrm{g} / \mathrm{ml}$ & $4.0 \%$ \\
\hline Level 5 & $518 \mu \mathrm{g} / \mathrm{ml}$ & $6.2 \%$ & & \\
\hline Level 6 & $1295 \mu \mathrm{g} / \mathrm{ml}$ & $3.3 \%$ & & \\
\hline Precision & \multicolumn{2}{|c|}{$\begin{array}{l}\text { Repeatability/intermediate } \\
\text { precision (RSD\%) }\end{array}$} & \multicolumn{2}{|c|}{$\begin{array}{l}\text { Repeatability/intermediate } \\
\text { precision (RSD\%) }\end{array}$} \\
\hline Level 1 & \multicolumn{2}{|c|}{$15.0 / 17.0$} & \multicolumn{2}{|l|}{$0.8 / 3.5$} \\
\hline Level 2 & \multicolumn{2}{|l|}{$4.2 / 4.2$} & \multicolumn{2}{|l|}{$0.8 / 4.8$} \\
\hline Level 3 & \multicolumn{2}{|l|}{$4.4 / 4.4$} & \multicolumn{2}{|l|}{$4.2 / 4.7$} \\
\hline Level 4 & \multicolumn{2}{|l|}{$3.1 / 3.3$} & \multicolumn{2}{|l|}{$2.9 / 4.1$} \\
\hline Level 5 & \multicolumn{2}{|l|}{$2.1 / 2.1$} & & \\
\hline Level 6 & \multicolumn{2}{|l|}{$2.4 / 2.7$} & & \\
\hline Accuracy & \multicolumn{2}{|c|}{$\begin{array}{l}\beta \text {-expectation lower and } \\
\text { upper tolerance limits of the } \\
\text { relative error }(\%)\end{array}$} & \multicolumn{2}{|c|}{$\begin{array}{l}\beta \text {-expectation lower and } \\
\text { upper tolerance limits in } \\
\text { relative error }(\%)\end{array}$} \\
\hline Level 1 & \multicolumn{2}{|l|}{$-47.8 ; 41.1$} & \multicolumn{2}{|l|}{$-8.0 ; 24.7$} \\
\hline Level 2 & \multicolumn{2}{|l|}{$-11.6 ; 9.1$} & \multicolumn{2}{|l|}{$-19.0 ; 26.4$} \\
\hline Level 3 & \multicolumn{2}{|l|}{$-10.1 ; 11.6$} & \multicolumn{2}{|l|}{$-10.1 ; 13.8$} \\
\hline Level 4 & \multicolumn{2}{|l|}{$-6.4 ; 10.5$} & \multicolumn{2}{|l|}{$-8.2 ; 16.1$} \\
\hline Level 5 & \multicolumn{2}{|l|}{$1.1 ; 11.4$} & & \\
\hline Level 6 & \multicolumn{2}{|l|}{$-3.6 ; 10.1$} & & \\
\hline \multicolumn{5}{|l|}{ Linearity } \\
\hline Slope & \multicolumn{2}{|l|}{1.035} & 1.040 & \\
\hline Intercept & 0.5372 & & -5.441 & \\
\hline$r^{2}$ & 0.9989 & & 0.9977 & \\
\hline
\end{tabular}




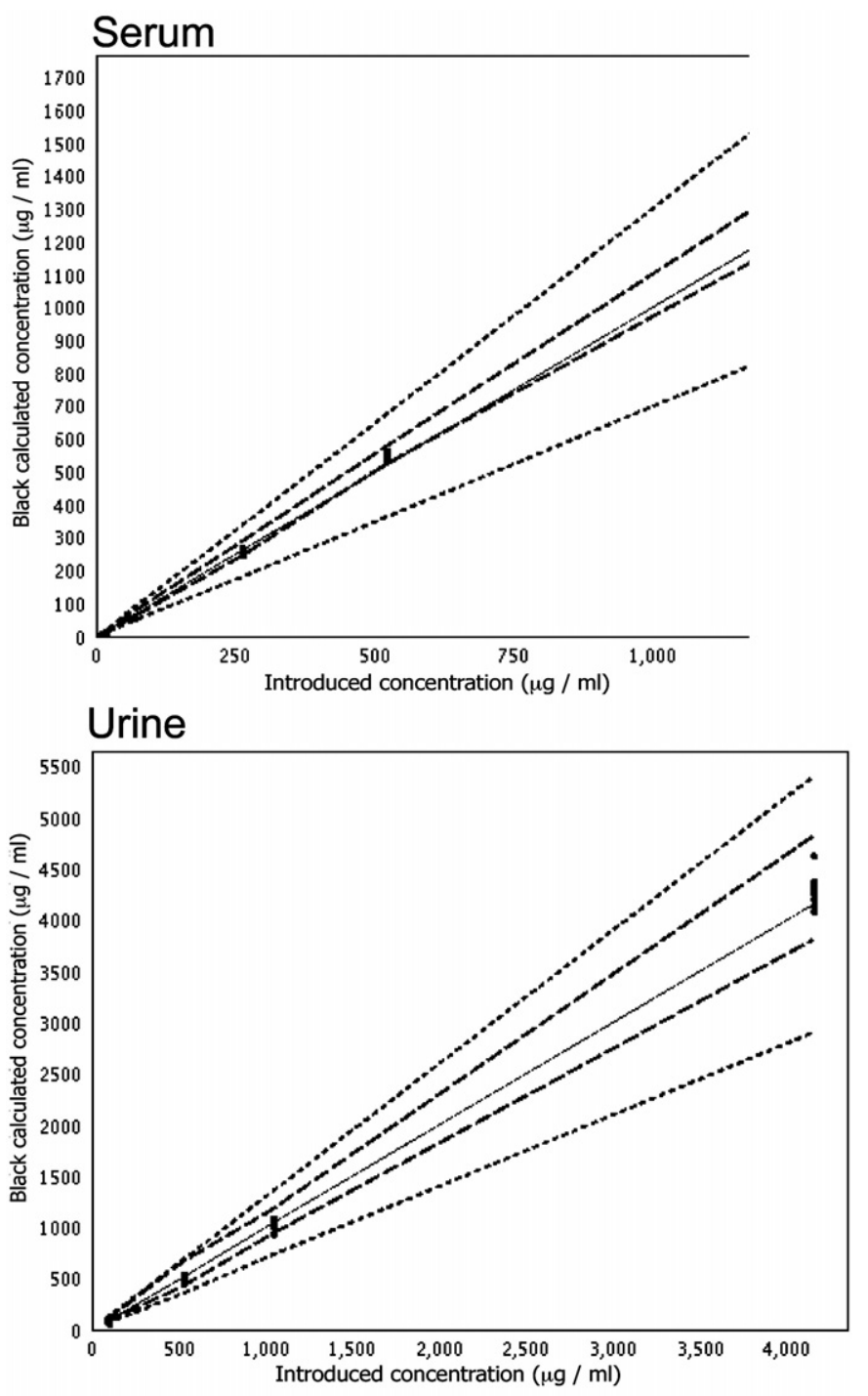

Fig. 3. Linearity profiles for serum and urine. Identity line (_ $\_$) when $Y=X$, upper and lower acceptance limits in absolute values (....), and upper and lower $\beta$-expectation tolerance limits (----).

Thus the method can be considered as giving accurate results between 12.95 and $1295 \mu \mathrm{g} / \mathrm{ml}$ for serum samples, and between 86.0 and $4144 \mu \mathrm{g} / \mathrm{ml}$ for urine.

The limit of detection (smallest quantity of the analyte than can be detected in the sample, but not quantified) was evaluated at $3.08 \mu \mathrm{g} / \mathrm{ml}$ for serum and $26.06 \mu \mathrm{g} / \mathrm{ml}$ for urine. The limits of quantification, obtained by calculating the smallest and the highest concentration beyond, which the $\beta$-expectation limits go outside the acceptance limits were 10.76 and $1295 \mu \mathrm{g} / \mathrm{ml}$ for the lowest and highest limits for serum, respectively. For urine, they were at 86.0 and $4144 \mu \mathrm{g} / \mathrm{ml}$.

\subsubsection{Linearity of the results}

To evaluate the linearity of the method results, a linear regression line was fitted on the back-calculated concentrations of the validation standards $[16,24,26]$. The equations obtained and the coefficients of determination are shown in Table 1 . The linearity was demonstrated using the $\beta$-expectation tolerance interval approach, as the absolute upper and lower $\beta$-expectation tolerance limits were included inside the absolute acceptance limits, irrespective of the concentrations studied (Fig. 3).

\subsection{Risk assessment}

The effective risk of having a future measurement falling outside the specified acceptance limits of $\pm 30 \%$ total error by using the $\beta$ expectation tolerance intervals obtained with the selected regression models was also evaluated. This risk is calculated as the sum of the proportion of results lying above the upper and under the lower acceptance limits for each concentration level tested [27]. The maximum risk tolerated was set at $5 \%$, it means that in routine practice, we do not accept no more than $5 \%$ of our samples to fall outside the $\pm 30 \%$ acceptance limits, which is acceptable in clinical biology. Fig. 4 shows the risk profile associated at each level studied for both matrices. None of the levels included in the validated range presented a risk higher than $5 \%$ for serum. However for the lowest concentration tested $(8.63 \mu \mathrm{g} / \mathrm{ml})$ where the method is not anymore valid the effective risk to obtain a result out of the acceptance limits is of about 22\%. For urine samples, the risk associated to all the concentration levels tested is well under the maximum risk of $5 \%$ reaching its maximum value $3.7 \%$ for the $518 \mu \mathrm{g} / \mathrm{ml} \mathrm{level.} \mathrm{The}$ integration of the risk profile in the validation process allows us to determine how far our method will be reliable for its routine utilisation by knowing the effective risk of obtaining out of specification results during the future routine use of the method.
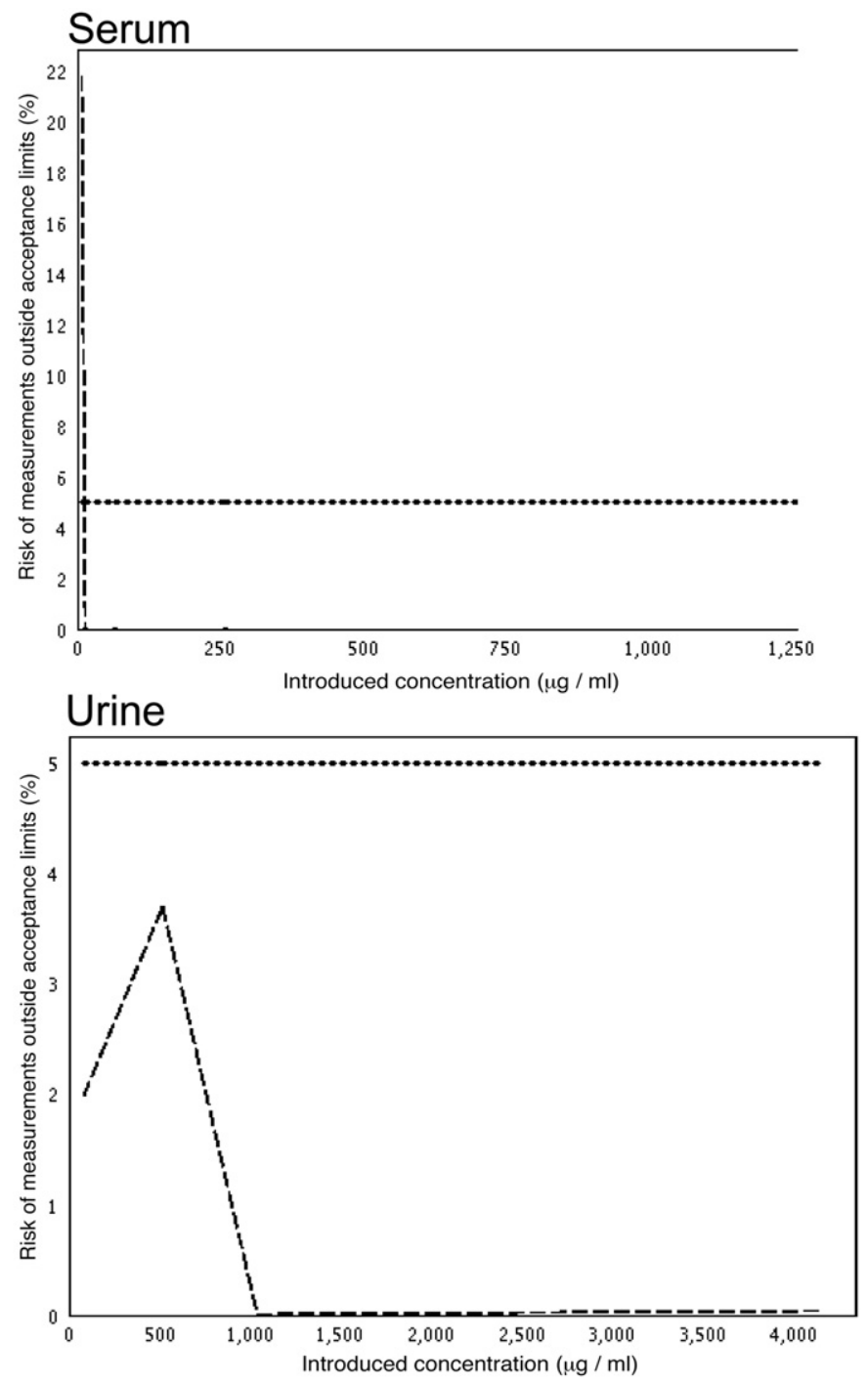

Fig. 4. Risk profiles for serum and urine. The maximum tolerated risk is set at $5 \%$. 
Table 2

Estimates of measurement uncertainties related to iohexol measurement in serum and urine, at each concentration level investigated.

\begin{tabular}{|c|c|c|c|c|c|}
\hline SERUM & Concentration $(\mu \mathrm{g} / \mathrm{ml})$ & Uncertainty of the bias $(\mu \mathrm{g} / \mathrm{ml})$ & Uncertainty $(\mu \mathrm{g} / \mathrm{ml})$ & Expanded uncertainty $(\mu \mathrm{g} / \mathrm{ml})$ & Relative uncertainty (\%) \\
\hline Level 1 & 8.63 & 0.59 & 1.58 & 3.16 & 36.7 \\
\hline Level 2 & 12.95 & 0.18 & 0.58 & 1.16 & 8.9 \\
\hline Level 3 & 64.75 & 0.96 & 3.02 & 6.05 & 9.3 \\
\hline Level 4 & 259.0 & 3.19 & 9.22 & 18.44 & 7.1 \\
\hline Level 5 & 518.0 & 3.62 & 11.44 & 22.89 & 4.4 \\
\hline Level 6 & 1295 & 13.33 & 37.10 & 74.20 & 5.7 \\
\hline URINE & Concentration $(\mu \mathrm{g} / \mathrm{ml})$ & Uncertainty of the bias $(\mu \mathrm{g} / \mathrm{ml})$ & Uncertainty $(\mu \mathrm{g} / \mathrm{ml})$ & Expanded uncertainty $(\mu \mathrm{g} / \mathrm{ml})$ & Relative uncertainty (\%) \\
\hline Level 1 & 86.00 & 1.71 & 3.47 & 6.94 & 8.1 \\
\hline Level 2 & 518.0 & 14.07 & 28.35 & 56.70 & 10.9 \\
\hline Level 3 & 1036 & 18.65 & 51.72 & 103.4 & 9.9 \\
\hline Level 4 & 4144 & 78.55 & 185.6 & 371.1 & 8.9 \\
\hline
\end{tabular}

\subsection{Uncertainty assessment}

The uncertainty characterizes the dispersion of the values that could reasonably be attributed to the measurand [28]. Several uncertainty results were generated and are presented in Table 2: the uncertainty of bias of the method at each concentration level of the validation standard, the uncertainty, which combines the uncertainty of the bias with the uncertainty of the method obtained during the validation step, i.e. the intermediate precision standard deviation, and the expanded uncertainty, which equals to the uncertainty multiplied by a coverage factor $k=2$, representing an interval around the results where the unknown true value can be observed with a confidence level of 95\% [28]. In addition, the relative expanded uncertainties (\%) sor serum and urine obtained by dividing the corresponding expanded uncertainties with the corresponding introduced concentrations (Table 2) are not higher than $10 \%$, which means that with a confidence level of $95 \%$, the unknown true value is located at a maximum of $\pm 10 \%$ around the measured result. Only for the first concentration level of iohexol in serum $(8.63 \mu \mathrm{g} / \mathrm{ml})$ is the relative expended uncertainty extremely high, about $36 \%$.

\section{Discussion}

A simple HPLC/UV method for iohexol determination in serum and urine was successfully analytically validated. This is the first time that a reference method for the determination of GFR is validated with such a rigorous and thorough protocol. Contrary to other GFR markers, iohexol is now strongly validated from an analytical point of view and the method is now ready for its clinical application. Moreover, iohexol determination in urine has been poorly studied. Now, on particular conditions and especially in patients with ascite or interstitial oedema, the accurate measure of the urinary clearance is of importance and better than the plasma clearance [29]. Moreover, the reproducibility of GFR measurement is relatively high (around 10\%). This reproducibility could certainly be improved if the analytical performance of the marker used for determination (inulin, isotopic or contrast agent) was improved [30,31].

The validation results indicate that the method will give accurate and reliable results for serum values ranging from 12.95 to $1295 \mu \mathrm{g} / \mathrm{ml}$ and for urine values ranging from 86.0 to $4144 \mu \mathrm{g} / \mathrm{ml}$. In routine practice, iohexol concentrations found in plasma after injection of $5 \mathrm{ml}$ of Omnipaque ${ }^{\circledR}(520 \mu \mathrm{g} / \mathrm{ml})$ usually range from 40 to $600 \mu \mathrm{g} / \mathrm{ml}$, related to the renal status of the patient and the delay between injection and sampling. The expected urinary values are much wider, depending on the hydratation and the renal function of the patients. As the response of the detector is no linear any more over $4144 \mu \mathrm{g} / \mathrm{ml}$, one should not hesitate to dilute urine samples to fit with the validated range over $4144 \mu \mathrm{g} / \mathrm{ml}$. Indeed, urine values usually found in our experience can range from $700 \mu \mathrm{g} / \mathrm{ml}$ to more than $12000 \mu \mathrm{g} / \mathrm{ml}$. These values are much higher than what had previously been validated for urinary iohexol $(10-50 \mu \mathrm{g} / \mathrm{ml})$ [32].
The original validation approach applied, using accuracy profiles based on $\beta$-expectation tolerance intervals for the total measurement error, allowed to evaluate the capability of the method to give fit for purpose results. The concept of accuracy profile was also used to select the most appropriate regression model for calibration, to determine the limit of quantification (LOQ) and the range over, which the method can be considered as valid.

Moreover, the risk with respect to the future use of the validated method was estimated and it was demonstrated to be lower than 5\% over the whole validated range of concentration for both matrices. Finally, the measurement uncertainties were estimated, allowing correct interpretation and comparison of the results.

From an analytical point of view, we have shown that iohexol determination by HPLC/UV is accurate to meet the clinical goals in GFR measurement.

\section{Acknowledgment}

Thanks are due to the Fonds Leon Fredericq and the University of Liège for a research grant to Eric Rozet.

\section{References}

[1] Smith H. The kidney: structure and function in health and disease. New York: Oxford University Press; 1951.

[2] Brandstrom E, Grzegorczyk A, Jacobsson L, Friberg P, Lindahl A, Aurell M. GFR measurement with iohexol and 51Cr-EDTA. A comparison of the two favoured GFR markers in Europe. Nephrol Dial Transplant 1998;13:1176-82.

[3] Perrone RD, Madias NE, Levey AS. Serum creatinine as an index of renal function: new insights into old concepts. Clin Chem 1992;38:1933-53.

[4] Delanaye P, Lambermont B, Chapelle JP, Gielen J, Gerard P, Rorive G. Plasmatic cystatin $\mathrm{C}$ for the estimation of glomerular filtration rate in intensive care units. Intensive Care Med 2004;30:980-3.

[5] Mariat C, Maillard N, Phayphet M, et al. Estimated glomerular filtration rate as an end point in kidney transplant trial: where do we stand? Nephrol Dial Transplant 2008;23:33-8.

[6] Brochner-Mortensen J, Giese J, Rossing N. Renal inulin clearance versus total plasma clearance of 51Cr-EDTA. Scand J Clin Lab Invest 1969;23:301-5.

[7] Rootwelt K, Falch D, Sjokvist R. Determination of glomerular filtration rate (GFR) by analysis of capillary blood after single shot injection of 99mTc-DTPA. A comparison with simultaneous 125I-iothalamate GFR estimation showing equal GFR but difference in distribution volume. Eur J Nucl Med 1980;5:97-102.

[8] Brown SC, O'Reilly PH. Iohexol clearance for the determination of glomerular filtration rate in clinical practice: evidence for a new gold standard. JUrol 1991;146: 675-9.

[9] Frennby B, Sterner G. Contrast media as markers of GFR. Eur Radiol 2002:12:475-84

[10] Malamos B, Dontas AS, Koutras DA, Marketos S, Sfontouris J, Papanicolaou N. 125Isodium iothalamate in the determination of the glomerular filtration rate. Nucl Med (Stuttg) 1967;6:304-10.

[11] Back SE, Masson P, Nilsson-Ehle P. A simple chemical method for the quantification of the contrast agent iohexol, applicable to glomerular filtration rate measurements. Scand J Clin Lab Invest 1988;48:825-9.

[12] Krutzen E, Back SE, Nilsson-Ehle I, Nilsson-Ehle P. Plasma clearance of a new contrast agent, iohexol: a method for the assessment of glomerular filtration rate. J Lab Clin Med 1984;104:955-61.

[13] Shihabi ZK, Constantinescu MS. Iohexol in serum determined by capillary electrophoresis. Clin Chem 1992;38:2117-20.

[14] International conference on harmonization (ICH) of technical requirements for registration of pharmaceuticals for human use, topic Q2 R1. Validation of analytical procedures: text and methodology. 2005. Geneva. 2005. 
[15] ISO 5725-1, Application of the statistics-accuracy (trueness and precision) of the results and methods of meassurement-Part 1: General principles and definitions. International Organization for Standardization (ISO). 2005. Geneva.

[16] Hubert P, Nguyen-Huu JJ, Boulanger B, et al. Harmonization of strategies for the validation of quantitative analytical procedures. A SFSTP proposal-Part I. J Pharm Biomed Anal 2004;36:579-86.

[17] Guidance for idustry: Bioanalytical Mathod Validation, US Department of Health and Human Services, Food and Drug Administration, Center for Drug Evaluation and Research (CDER), Center for Biologics Evaluation and Research (CBER). 2001. Rockville.

[18] The fitness for purpose of analytical methods: a laboratory guide to method validation and related topics. Teddington: Eurachem; 1998.

[19] International vocabulary of basic and general terms in metrology. Geneva: ISO; 1993.

[20] Feinberg M, Boulanger B, Dewe W, Hubert P. New advances in method validation and measurement uncertainty aimed at improving the quality of chemical data. Anal Bioanal Chem 2004;380:502-14

[21] EURACHEM/CITAC Guide CG 4; Quantifying uncertainty in analytical measurement Second Edition. 2000

[22] Vardeman SB. What about the other intervals? The American Statistician 1992;46:193-6.

[23] Hahn GJ and Meeker WQ. Statistical intervals: a guide for practitioners. Wiley Edition, 392, 1991 September.

[24] Rozet E, Ceccato A, Hubert C, et al. Analysis of recent pharmaceutical regulatory documents on analytical method validation. J Chromatogr A 2007;1158:111-25.
[25] Rozet E, Hubert C, Ceccato A, et al. Using tolerance intervals in pre-study validation of analytical methods to predict in-study results. The fit-for-future-purpose concept. J Chromatogr A 2007;1158:126-37.

[26] Hubert P, Nguyen-Huu JJ, Boulanger B, et al. Harmonization of strategies for the validation of quantitative analytical procedures. A SFSTP proposal-part III. J Pharm Biomed Anal 2007;45:82-96.

[27] Rozet E, Morello R, Lecomte F, et al. Performances of a multidimensional on-line SPE-LC-ECD method for the determination of three major catecholamines in native human urine: validation, risk and uncertainty assessments. J Chromatogr B Analyt Technol Biomed Life Sci 2006;844:251-60.

[28] Linko S, Ornemark U, Kessel R, Taylor PD. Evaluation of uncertainty of measurement in routine clinical chemistry-applications to determination of the substance concentration of calcium and glucose in serum. Clin Chem Lab Med 2002;40:391-8.

[29] Skluzacek PA, Szewc RG, Nolan III CR, Riley DJ, Lee S, Pergola PE. Prediction of GFR in liver transplant candidates. Am J Kidney Dis 2003;42:1169-76.

[30] Agarwal R. Reproducibility of renal function measurements in adult men with diabetic nephropathy: research and clinical implications. Am J Nephrol 2007;27:92-100.

[31] Apperloo AJ, de Zeeuw D, Donker AJ, de Jong PE. Precision of glomerular filtration rate determinations for long-term slope calculations is improved by simultaneous infusion of 125I-iothalamate and 131I-hippuran. J Am Soc Nephrol 1996;7:567-72.

[32] Farthing D, Sica DA, Fakhry I, et al. Simple HPLC-UV method for determination of iohexol, iothalamate, p-aminohippuric acid and n-acetyl-p-aminohippuric acid in human plasma and urine with ERPF, GFR and ERPF/GFR ratio determination using colorimetric analysis. J Chromatogr B Analyt Technol Biomed Life Sci 2005;826: 267-72. 